\title{
Physiological changes during symptom recovery from moderate exacerbations of COPD
}

\author{
C.M. Parker*, N. Voduc*, S.D. Aaron" ${ }^{\#}$ K.A. Webb* and D.E. O’Donnell*
}

ABSTRACT: Acute exacerbations of chronic obstructive disease (AECOPD) are characterised by worsening dyspnoea that is variably prolonged. In this study, physiological changes during moderate AECOPD were examined and the factors associated with dyspnoea resolution over time were determined.

In total, 20 patients experiencing an AECOPD were evaluated within $72 \mathrm{~h}$ of initial worsening of symptoms (day 0 ) with pulmonary function testing, metabolic testing and symptom assessment using the dyspnoea domain of the Chronic Respiratory Disease Questionnaire (CRQ). Treatment was optimised and testing was repeated after 7, 14, 30 and 60 days.

At day 0, patients were very short of breath (CRQ-dyspnoea mean \pm SEM $2.4 \pm 0.3$ ) and showed significant airflow obstruction (forced expiratory volume in one second (FEV 1 ) $41 \pm 3 \%$ predicted) and lung hyperinflation (forced residual capacity (FRC) $164 \pm 7 \%$ pred). By day 60 CRQ-dyspnoea improved to $4.6 \pm 0.5$ (some shortness of breath); FRC and residual volume decreased by 5 and $11 \%$, respectively; inspiratory capacity (IC) and slow vital capacity increased by 18 and 17\%, respectively; and $F_{E V} 1$ increased by $18 \%$ with no change in FEV $1 / F V C$. Total lung capacity did not change during AECOPD, and thus, changes in IC reliably reflected changes in end-expiratory lung volume.

In conclusion, moderate acute exacerbation of chronic obstructive pulmonary disease is characterised by worsening airflow obstruction and lung hyperinflation. Improvement of dyspnoea following acute exacerbations of chronic obstructive pulmonary disease was associated with reduction in lung hyperinflation and consequent increase in expiratory flow rates.

KEYWORDS: Chronic obstructive pulmonary disease, dyspnoea, exacerbation, lung hyperinflation

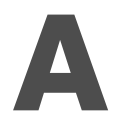
cute exacerbations of chronic obstructive pulmonary disease (AECOPD) can lead to considerable morbidity and mortality. Such exacerbations are known to have highly variable clinical manifestations, which may reflect the heterogeneous underlying pathophysiology of this condition, as well as differences in response to various triggering events. Most operational definitions of AECOPD make reference to sustained worsening of dyspnoea as a characteristic feature [1-3]. Indeed, dyspnoea that is refractory to usual bronchodilator therapy is often the most distressing symptom during AECOPD and is frequently the primary reason for seeking medical attention. SEEMUNGAL et al. [4] have recently demonstrated that some patients may remain dyspnoeic for considerable periods of time and that this, in turn, may contribute to activity limitation and perceived poor health status in these individuals [5].

For editorial comments see page 376 .
Despite its prominence as a defining symptom, no previous studies have systematically examined potential mechanisms of dyspnoea in this setting. Although the mechanical and gas exchange abnormalities of severe exacerbations associated with acute respiratory failure in hospitalised patients undergoing mechanical ventilation (MV; invasive or noninvasive) are well documented [6-10], knowledge of the pathophysiological underpinnings of dyspnoea during less severe exacerbations is incomplete. Based on previous studies of the mechanisms of exertional dyspnoea in COPD, the current authors postulated that acute lung hyperinflation would also contribute importantly to dyspnoea during AECOPD [11-13].

Currently, it is believed that acute airway mucosal inflammation, in response to inciting triggers such as infection or pollution, is a major cause of AECOPD [14, 15]. It is reasonable to assume that this inflammatory response is associated with worsening expiratory flow limitation, which can compromise lung emptying during

\section{AFFILIATIONS}

*Dept of Medicine, Queen's University, Kingston, and

\# Ottawa Health Research Institute, University of Ottawa, Ottawa, Canada.

CORRESPONDENCE

D. O'Donnell

102 Stuart Street

Kingston

Ontario

Canada

K7L 2V6

Fax: 16135491459

E-mail: odonnell@post.queensu.ca

Received:

November 292004

Accepted after revision:

April 202005

SUPPORT STATEMENT

This study was supported by Bayer Inc. and the Ontario Ministry of Health (Toronto, Canada).
European Respiratory Journal Print ISSN 0903-1936 Online ISSN 1399-3003 
tidal expiration to such a degree that resting end-expiratory lung volume (EELV) is dynamically increased above baseline values. Lung hyperinflation in some patients may be further aggravated by concomitant increase in ventilatory demand as a result of acute ventilation/perfusion abnormalities [6]. Acuteon-chronic lung hyperinflation would constrain tidal volume expansion and cause increased loading and weakness of the inspiratory muscles. The net effect of all of these adverse physiological events is a disparity between the neural drive to breathe and the mechanical response of the respiratory system. It has previously been argued that this "neuromechanical dissociation" may form the basis for acute symptomatic deterioration during exercise in COPD [11-13].

Therefore, the hypothesis presented in this paper was that acute lung hyperinflation is an important contributor to respiratory discomfort during exacerbations. It follows that recovery of dyspnoea following an AECOPD would be associated with reduction in lung hyperinflation. A prospective, observational study was conducted where patients diagnosed as having an AECOPD, who did not require MV, were referred for detailed physiological testing and symptom assessment and, thereafter, followed at pre-determined intervals over a 60 -day period. Finally, to determine the potential practical utility of using simple inspiratory capacity (IC) measurements to evaluate the severity and recovery of AECOPD, the reliability of this measurement to track changes in EELV was assessed.

\section{METHODS}

\section{Subjects}

Between December 2001 and December 2003, patients suspected of having an AECOPD were referred from family doctors' offices and from the emergency department of a tertiary care teaching hospital. All patients were enrolled and tested within $72 \mathrm{~h}$ of the onset of their symptomatic deterioration. Inclusion criteria were: 1 ) age $\geqslant 50 \mathrm{yrs} ; 2$ ) a history compatible with COPD $[16,17]$; and 3) a presentation compatible with a moderate AECOPD [1, 3, 16]. Where possible, pre-exacerbation (i.e. baseline) pulmonary function tests were evaluated to corroborate the diagnosis of COPD. An acute exacerbation was defined according to the criteria adopted by the Canadian Thoracic Society, "a sustained worsening of dyspnoea, cough or sputum production leading to an increase in the use of maintenance medication and/or supplementation with additional medications" [2]. A moderate exacerbation was defined according to the classification schema proposed by RoDRIGUEZ-RoISIN [1], where the patient "has an increased need for medication and feels the need to seek additional medical assistance". Exclusion criteria were: 1) respiratory failure requiring invasive or noninvasive $\mathrm{MV}$; 2 ) haemodynamic instability; 3 ) the presence of another acute condition (e.g. pneumonia, congestive heart failure, pulmonary embolus) to explain the presentation; 4) inability to comply with testing; 5) multiple comorbidities; or 6) the presence of another chronic lung disease (e.g. asthma).

\section{Study design}

The study design was reviewed and approved by the local hospital/university (Queens University and Affiliated Teaching hospitals, Kingston, Ontario, Canada) ethics committee and written informed consent was obtained from all participants.
Subjects were evaluated at day 0 (study entry) and at days 14 , 30 , and 60 post-enrollment. A smaller subset of patients $(n=8)$ was also evaluated at day 7. Demographic data were collected at day 0 , including age, smoking history, comorbidities, oxygen use and medication history. At each visit, subjects underwent symptom assessment, pulmonary function testing and measurement of metabolic and breathing pattern parameters. Patients were managed either as outpatients or as inpatients on a general medicine or respiratory ward. Inpatient exacerbations were treated according to the most recent guidelines established by the Canadian Thoracic Society [2] and could include bronchodilators, corticosteroids and antibiotics. Bronchodilator dose was not specifically standardised between patients, and bronchodilators could be administered via metered-dose inhalers, with or without a spacer device, or given by nebulisation. Oxygen therapy was allowed if required to maintain an arterial oxygen saturation $\left(\mathrm{Sa}_{2} \mathrm{O}_{2}\right)$ of $>90 \%$, and flow rates were titrated accordingly. Management of outpatient exacerbations was left to the discretion of the family physician, although antibiotics were recommended for all patients with two of the following clinical features: 1) increased dyspnoea; 2) increased sputum production; and 3) increased sputum purulence. All patients were followed-up by their family physicians to evaluate their response to treatment. At day 0, the time interval between last bronchodilator use and testing was recorded for each patient and a similar time interval was used at subsequent visits for that patient. Patients who missed a visit were allowed to continue in the study and all available visits were included in the analysis.

\section{Procedures}

\section{Symptom assessment}

A simple questionnaire was used to record the presence of dyspnoea, cough and sputum. Dyspnoea intensity was rated using the dyspnoea dimension of the Chronic Respiratory Disease Questionnaire (CRQ) [18], the 10-point Borg scale [19] and the modified Medical Research Council (MRC) dyspnoea scale [20]. The dyspnoea component of the CRQ evaluates shortness of breath on a scale of 1-7 (from "extremely short of breath" to "not at all short of breath") for a list of five important activities individualised for each patient with the mean value for these activities reported. This scale has been shown to be reproducible and responsive [18]. The CRQ questionnaire was adapted for this study by replacing the words "during the last 2 weeks" with "during the last few days." Activity-related dyspnoea at day 0 was also assessed using the Baseline Dyspnoea Index (BDI), while changes from day 0 at subsequent visits were monitored with the Transition Dyspnoea Index (TDI) [21]. At each visit, patients were asked whether the severity of their dyspnoea had returned to their pre-exacerbation level. Patients who reported that their dyspnoea intensity had returned to its pre-exacerbation level were classified as "symptomatically recovered," whereas patients who reported a dyspnoea intensity that was persistently greater than their pre-exacerbation level were classified as "symptomatically nonrecovered."

\section{Pulmonary function tests}

Routine spirometry [22], including measurement of forced vital capacity (FVC), forced expiratory volume in one second (FEV1) and peak expiratory flow rate (PEFR), was performed using 
automated testing equipment (Vmax229d; SensorMedics, Yorba Linda, CA, USA). Measurement of lung volumes, including IC, slow vital capacity (SVC), functional residual capacity (FRC), residual volume (RV) and total lung capacity (TLC), as well as specific airway resistance (sRaw) was determined by constant-volume body plethysmography (6200 Body Plethysmograph; SensorMedics), with a panting frequency of $1 \mathrm{~Hz}$. Single-breath diffusing capacity for carbon monoxide (DL,CO) was also measured (Vmax229d; SensorMedics). Pulmonary function measurements were evaluated as percentages of predicted normal values [23-27], with predicted IC derived as predicted TLC minus predicted FRC.

\section{Metabolic measurements and breathing pattern analysis}

Metabolic and breathing pattern parameters were measured using a metabolic cart (Vmax 229d; SensorMedics). Subjects sat quietly at rest and breathed room air through a mouthpiece with noseclips for $>3$ min until a steady-state was reached. Measurements included: minute ventilation $\left(V^{\prime} \mathrm{E}\right)$; oxygen consumption $\left(V^{\prime} \mathrm{O}_{2}\right)$; and carbon dioxide production $\left(V^{\prime} \mathrm{CO}_{2}\right)$. Breathing pattern parameters included tidal volume $(V \mathrm{~T})$, breathing frequency $(f)$, inspiratory time, expiratory time and total breathing cycle time. $\mathrm{Sa}_{1} \mathrm{O}_{2}$ was assessed by pulse oximetry (Sat Trak; SensorMedics). Arterial blood gases were measured in patients with a room air $\mathrm{Sa}_{2} \mathrm{O}_{2}<90 \%$ or at the discretion of the treating physician.

\section{Statistical analysis}

Results are reported as mean \pm SEM. A $p<0.05$ significance level was used for all analyses. Within- and between-group comparisons were made using statistical methods for repeated measures and longitudinal data. Multivariate correlative analysis was not performed given the interdependence of the variables studied.

A sample size of 20 was required in order to have the power to detect a significant difference in IC. The sample size calculation was made using the following assumptions: 1) a relevant reduction in IC of $>0.30 \mathrm{~L}$ ( $\sim 10 \%$ pred) between baseline and recovery; 2 ) a SD for change in IC of $0.34 \mathrm{~L}$ ( $\sim 12 \%$ pred) based on previous values from the authors' laboratory for a large group of COPD patients, $\alpha=0.05, \beta=0.20$ (80\% power) and a two-tailed test of significance.

\section{RESULTS}

\section{Subjects}

In total, 32 patients were evaluated for possible inclusion into the study. Of these, 25 were referred by their primary care physicians and seven referred from the hospital emergency department. Twelve of these patients were subsequently excluded from the study because they were unable to comply with testing $(n=3)$, had pulmonary function tests at day 0 that were not compatible with a diagnosis of COPD $(n=3)$, did not meet the definition for AECOPD $(n=1)$ or did not meet other inclusion criteria $(n=5)$. Ultimately, 20 patients were enrolled and included in the study analysis.

Demographic and symptom assessment data collected at study entry (day 0 ) are presented in table 1 . In 16 out of the 20 patients, the diagnosis of COPD was corroborated with pulmonary function tests obtained prior to the exacerbation. The majority $(65 \%)$ of patients were managed as outpatients.

\begin{tabular}{|c|c|}
\hline & Value \\
\hline \multicolumn{2}{|l|}{ Demographics } \\
\hline Male/female $\mathrm{n}$ & $7 / 13$ \\
\hline Age yrs & $65 \pm 2$ \\
\hline Height $\mathrm{cm}$ & $164 \pm 2$ \\
\hline Weight kg & $70.5 \pm 4.0$ \\
\hline Body mass index $\mathrm{kg} \cdot \mathrm{m}^{-2}$ & $26.2 \pm 1.5$ \\
\hline Outpatients/hospitalised n & $13 / 7$ \\
\hline \multicolumn{2}{|l|}{ Smoking History } \\
\hline Cigarette use pack-yrs & $54 \pm 6$ \\
\hline Current smokers $n$ & 45 \\
\hline \multicolumn{2}{|l|}{ Symptoms } \\
\hline Increased dyspnoea & 100 \\
\hline Increased cough & 80 \\
\hline Increased sputum production & 70 \\
\hline Change in sputum colour & 65 \\
\hline CRQ dyspnoea domain score & $2.4 \pm 0.3$ \\
\hline Modified MRC dyspnoea score & $3.0 \pm 0.2$ \\
\hline Dyspnoea intensity at rest Borg scale & $2.9 \pm 0.3$ "moderate" \\
\hline Baseline dyspnoea index focal score & $3.9 \pm 0.4$ \\
\hline \multicolumn{2}{|l|}{ Medication use } \\
\hline \multicolumn{2}{|l|}{ Pre-exacerbation "baseline" } \\
\hline Bronchodilators (long and short acting) & 100 \\
\hline Inhaled corticosteroids & 70 \\
\hline Systemic corticosteroids & 0 \\
\hline Oxygen therapy & 5 \\
\hline \multicolumn{2}{|l|}{ During exacerbation } \\
\hline New or increased bronchodilators & 100 \\
\hline New or increased inhaled corticosteroids & 15 \\
\hline New or increased systemic corticosteroids & 60 \\
\hline New or increased oxygen therapy & 5 \\
\hline Antibiotics & 90 \\
\hline
\end{tabular}

Data are presented as mean \pm SEM or \% of patients unless otherwise stated. CRQ: Chronic Respiratory Disease Questionnaire; MRC: Medical Research Council. \#: $n=20$.

At day 0, all patients experienced worsened dyspnoea as a manifestation of AECOPD, and the majority also experienced worsening cough, an increase in sputum production or a change in sputum colour. Patients were breathless, reporting an average CRQ dyspnoea score of 2.4 (corresponding to feeling "quite a bit" to "very" short of breath with activity), an average MRC dyspnoea score of 3.0 ("stops for breath after walking about 100 yards or after a few minutes on the level") and an average BDI focal score of 3.9 (indicating severe impairment due to breathlessness).

Pulmonary function, metabolic and breathing pattern data collected at day 0 are presented in table 2 . Some patients were too dyspnoeic to complete various tests on their first visit. One patient could not perform body plethysmography, three patients could not complete single-breath $D \mathrm{~L}, \mathrm{CO}$ and two could not breathe on a mouthpiece with noseclips for the required $3 \mathrm{~min}$ of steady-state metabolic measurements. Although $\mathrm{Sa}_{1} \mathrm{O}_{2}$ on room air was $<90 \%$ in only two subjects 


\begin{tabular}{|c|c|c|}
\hline \multirow[t]{2}{*}{ TABLE 2} & \multicolumn{2}{|c|}{$\begin{array}{l}\text { Pulmonary function tests, metabolic data and } \\
\text { breathing pattern analysis obtained at study entry } \\
\text { (day 0) } \#\end{array}$} \\
\hline & & Value \\
\hline \multicolumn{3}{|c|}{ Pulmonary function } \\
\hline FEV1 L & & $0.92 \pm 0.06(41)$ \\
\hline FVC L & & $2.09 \pm 0.12(65)$ \\
\hline $\mathrm{FEV}_{1} / \mathrm{FVC}$ & & $44.2 \pm 2.0(63)$ \\
\hline PEFR L.S $S^{-1}$ & & $3.10 \pm 0.23(49)$ \\
\hline FEF25-75\% & & $0.31 \pm 0.03(13)$ \\
\hline IC L & & $1.53 \pm 0.11$ \\
\hline SVC L & & $2.40 \pm 0.16(75)$ \\
\hline TLC L & & $6.46 \pm 0.30(119)$ \\
\hline FRC L & & $4.91 \pm 0.29(164)$ \\
\hline RV L & & $4.07 \pm 0.26(197)$ \\
\hline sRaw $\mathrm{cmH}_{2}$ & $\cdot L^{-1} \cdot S^{-1} \cdot L^{-1}$ & $27.8 \pm 2.4(687)$ \\
\hline$D \mathrm{~L}, \mathrm{CO} / \mathrm{VA}, \mathrm{n}$ & $\cdot \mathrm{min}^{-1} \cdot \mathrm{mmHg} \cdot \mathrm{L}^{-1}$ & $2.89 \pm 0.18(76)$ \\
\hline \multicolumn{3}{|c|}{ Steady-state rest (room air) } \\
\hline Heart rate & eats $\cdot \min ^{-1}$ & $91 \pm 4$ \\
\hline $\mathrm{Sa}, \mathrm{O}_{2} \%$ & & $92.3 \pm 0.7$ \\
\hline$V^{\prime} \mathrm{O}_{2} \mathrm{~mL} \cdot \mathrm{kg}$ & $\cdot \min ^{-1}$ & $3.4 \pm 0.3$ \\
\hline$V^{\prime} \mathrm{O}_{2} L \cdot \mathrm{min}^{-}$ & & $0.23 \pm 0.02$ \\
\hline$V^{\prime} \mathrm{CO}_{2} \mathrm{~L} \cdot \mathrm{mir}$ & & $0.19 \pm 0.02$ \\
\hline Respiratory & exchange ratio & $0.85 \pm 0.02$ \\
\hline$V^{\prime} \mathrm{E} / \mathrm{V}^{\prime} \mathrm{CO}_{2}$ & & $61.9 \pm 4.2$ \\
\hline VD/VT estim & ted $\%$ & $49 \pm 2$ \\
\hline$V^{\prime} E L \cdot \min ^{-1}$ & & $11.6 \pm 0.7$ \\
\hline VT L & & $0.69 \pm 0.05$ \\
\hline VT \% pred & & $21 \pm 1$ \\
\hline$f$ breaths $\cdot m$ & & $17.9 \pm 1.2$ \\
\hline tI/tTOT & & $0.38 \pm 0.02$ \\
\hline $\mathrm{PET}, \mathrm{CO}_{2} \mathrm{mn}$ & & $36.5 \pm 1.1$ \\
\hline
\end{tabular}

Data are presented as mean \pm SEM (\% predicted). FEV 1 : forced expiratory volume in one second; FVC: forced vital capacity; PEFR: peak expiratory flow rate; FEF25-75\%: forced mid-expiratory flow; IC: inspiratory capacity; SVC: slow vital capacity; TLC: total lung capacity; FRC: functional residual capacity; RV: residual volume; sRaw: specific airway resistance; $D \mathrm{~L}, \mathrm{CO}$ : carbon monoxide diffusing capacity of the lung; $V_{A}$ : alveolar volume; $\mathrm{Sa}_{3} \mathrm{O}_{2}$ : arterial oxygen saturation; $V^{\prime} \mathrm{O}_{2}$ : oxygen consumption; $V^{\prime} \mathrm{CO}_{2}$ : carbon dioxide production; $V^{\prime} \mathrm{E}$ : minute ventilation; VD: volume of distribution; $V_{T}$ : tidal volume; $f$ : breathing frequency; $t \mathrm{l}$ : inspiratory time; $t$ TOT: total breathing cycle; $P \mathrm{ET}, \mathrm{CO}_{2}$ : end-tidal carbon dioxide tension. ${ }^{\#}: \mathrm{n}=20$, except for body plethysmography $(n=19)$, for single-breath $D L, C O(n=17)$ and for metabolic measurements $(n=18)$.

on day 0 , arterial blood gases were measured in nine patients (six out of the seven hospitalised patients and in three outpatients). In these patients the following values were observed: arterial oxygen tension $8.8 \pm 0.6 \mathrm{kPa}(66.5 \pm 4.4 \mathrm{mmHg})$; arterial carbon dioxide tension $5.78 \pm 03 \mathrm{kPa}(43.5 \pm 2.3 \mathrm{mmHg}) ; \mathrm{pH} 7.39 \pm 0.01$; bicarbonate $25.6 \pm 1.0 \mathrm{mmol} \cdot \mathrm{L}^{-1}$; and $\mathrm{Sa}, \mathrm{O}_{2} 90 \pm 1 \%$.

Prior to exacerbation, all patients were receiving bronchodilator therapy and the majority were using inhaled corticosteroids (table 1). During the exacerbation, all patients reported an increased need for bronchodilators, $60 \%$ were treated with systemic corticosteroids and $90 \%$ received antibiotic therapy. In five patients with persistent symptoms over the course of the study, further treatment with a second antibiotic was administered. Only one patient was using supplemental oxygen prior to exacerbation and this patient required an increased flow rate during the exacerbation.

\section{Recovery from COPD exacerbation}

The final visit for all 20 patients was conducted after an average of $60 \pm 5$ days. Given the nature of the condition and the testing under study, it is understandable that some patients were not able to complete all scheduled visits or tests. However, a majority of subjects $(n=18)$ completed a minimum of three study visits or were followed through until symptomatic recovery, while only two subjects withdrew from the study after completing only two visits. This limited loss of data points should not detract from the final relevance of this study.

During the follow-up period, 12 out of 20 patients reported that their dyspnoea intensity had returned to pre-exacerbation or baseline level ("symptomatically recovered" group). Symptom recovery in this group occurred after a mean of $41 \pm 6$ days of follow-up, and each of these patients returned for a final visit at day 60 . Of the remaining eight patients whose dyspnoea did not recover to baseline levels during the study period ("symptomatically nonrecovered" group), three were able to complete a final follow-up visit at day 60, two were too unwell to return for a final visit at day 60 and completed follow-up visits at approximately day 90 instead, and three patients were either too unwell to comply with further testing or experienced a worsening of their dyspnoea and withdrew from the study after completing visits at either day $14(n=2)$ or $30(n=1)$. Each of these subgroups was analysed separately to determine factors at presentation that might predict symptom improvement and to help identify physiological variables that correlate with recovery.

For the group as a whole, changes in symptoms and physiological variables are presented in table 3. During the study period, dyspnoea intensity progressively improved, with a significant change in the CRQ dyspnoea score of $1.6 \pm 0.4$ units between the first and last visits $(p<0.01)$. Similarly, dyspnoea intensity, as assessed by the MRC dyspnoea score and the resting Borg score, decreased significantly, and the average TDI measured at the final visit was $2.8 \pm 0.8$. Between day 0 and the final visit, IC and vital capacity (VC) increased, with reciprocal reductions in FRC and $\mathrm{RV}$, respectively. There was no significant change in TLC (fig. 1). This suggests that there was a progressive decrease in lung hyperinflation with time, and that a reduction in IC reliably predicts an increase in EELV. By day 14, maximal expiratory flows and $s$ aw had also improved relative to day 0 . Although FEV1 had increased by the last visit $(p<0.01)$, the FEV1/FVC ratio was unchanged. Aside from a modest increase in $\mathrm{Sa}, \mathrm{O}_{2}$ of $2.1 \pm 0.9 \%$ between the first and last visits, no other significant changes were observed in any of the other metabolic or breathing pattern parameters studied.

\section{Subgroup analysis}

At presentation, the symptomatically recovered group and the symptomatically nonrecovered group were similar in terms of demographics, although the nonrecovered group had a longer pack-year history of smoking ( $44 \pm 6$ versus $69 \pm 10$ pack-yrs; $\mathrm{p}<0.05)$. Both groups were also similarly dyspnoeic at 


\begin{tabular}{|c|c|c|c|c|c|}
\hline \multirow[t]{2}{*}{ TABLE 3} & $\begin{array}{l}\text { e exacerba } \\
\text { follow-up }\end{array}$ & onic obstru & ease as inc & y change & rements from stud) \\
\hline & Day 7 & Day 14 & Day 30 & Day 60 & Final visit \\
\hline Subjects $n$ & 8 & 17 & 15 & 15 & 20 \\
\hline Days post study entry & $7 \pm 1$ & $15 \pm 1$ & $30 \pm 1$ & $63 \pm 3$ & $60 \pm 5(14-92)$ \\
\hline \multicolumn{6}{|l|}{ Symptoms } \\
\hline TDI & $3.0 \pm 0.7^{\star \star}$ & $2.7 \pm 0.7^{\star \star}$ & $2.4 \pm 1.0^{*}$ & $3.3 \pm 0.9^{\star}$ & $2.8 \pm 0.8^{\star *}$ \\
\hline Dyspnoea at rest Borg & $-0.2 \pm 0.6$ & $-0.7 \pm 0.3$ & $-1.4 \pm 0.5^{\star}$ & $-1.1 \pm 0.5$ & $-1.6 \pm 0.4^{\star *}$ \\
\hline \multicolumn{6}{|l|}{ Pulmonary function } \\
\hline FEV1 L & $0.00 \pm 0.09$ & $0.12 \pm 0.06^{*}$ & $0.13 \pm 0.06^{*}$ & $0.24 \pm 0.06^{\star *}$ & $0.19 \pm 0.05^{\star \star}$ \\
\hline FEV $1 / F V C \%$ & $-2.5 \pm 2.4$ & $-0.2 \pm 2.1$ & $1.2 \pm 1.8$ & $2.0 \pm 1.9$ & $1.4 \pm 1.8$ \\
\hline SVC L & $0.27 \pm 0.10^{*}$ & $0.34 \pm 0.11^{\star \star}$ & $0.32 \pm 0.07^{\star \star}$ & $0.47 \pm 0.12^{\star \star}$ & $0.38 \pm 0.10^{\star *}$ \\
\hline TLC L & $0.07 \pm 0.15$ & $-0.00 \pm 0.09$ & $0.12 \pm 0.07$ & $0.13 \pm 0.07$ & $0.09 \pm 0.06$ \\
\hline FRC L & $0.00 \pm 0.12$ & $-0.28 \pm 0.09 * *$ & $-0.16 \pm 0.10^{*}$ & $-0.17 \pm 0.07^{\star}$ & $-0.20 \pm 0.06^{\star \star}$ \\
\hline$R V L$ & $-0.21 \pm 0.11$ & $-0.41 \pm 0.11^{* *}$ & $-0.20 \pm 0.11^{*}$ & $-0.34 \pm 0.12^{*}$ & $-0.31 \pm 0.10^{\star}$ \\
\hline sRaw \% pred & $-15 \pm 50$ & $-133 \pm 57^{\star}$ & $-67 \pm 57$ & $-128 \pm 51^{*}$ & $-102 \pm 43^{*}$ \\
\hline$D \mathrm{~L}, \mathrm{CO} / \mathrm{VA} \%$ pred & $6 \pm 1^{\star *}$ & $2 \pm 3$ & $-2 \pm 3$ & $1 \pm 3$ & $2 \pm 3$ \\
\hline \multicolumn{6}{|c|}{ Steady-state rest (room air) } \\
\hline $\mathrm{Sa}, \mathrm{O}_{2} \%$ & $0.4 \pm 0.2$ & $1.6 \pm 0.8$ & $1.5 \pm 0.5$ & $2.8 \pm 0.9^{*}$ & $2.1 \pm 0.9^{\star *}$ \\
\hline$V^{\prime} \mathrm{O}_{2} L \cdot \mathrm{min}^{-1}$ & $-0.00 \pm 0.02$ & $0.02 \pm 0.02$ & $0.02 \pm 0.02$ & $0.02 \pm 0.02$ & $0.01 \pm 0.02$ \\
\hline$V^{\prime} \mathrm{CO}_{2} \mathrm{~L} \cdot \mathrm{min}^{-1}$ & $0.00 \pm 0.01$ & $0.01 \pm 0.02$ & $0.02 \pm 0.02$ & $0.02 \pm 0.02$ & $0.01 \pm 0.02$ \\
\hline$V^{\prime} E L \cdot \min ^{-1}$ & $-1.8 \pm 1.1$ & $-0.7 \pm 0.6$ & $-0.1 \pm 0.5$ & $-0.3 \pm 0.7$ & $-0.3 \pm 0.6$ \\
\hline
\end{tabular}

Data are presented as mean \pm SEM. CRQ: Chronic Respiratory Disease Questionnaire; MRC: Medical Research Council dyspnoea score; TDI: transition dyspnoea index: FEV1: forced expiratory volume in one second; FVC: forced vital capacity; FEF25-75\%: forced mid-expiratory flow; PEFR: peak expiratory flow rate; IC: inspiratory capacity; SVC: slow vital capacity; TLC: total lung capacity; FRC: functional residual capacity; RV: residual volume; sRaw: specific airway resistance; DL,CO: carbon monoxide diffusing capacity of the lung; $V_{A}$ : alveolar volume; $\mathrm{Sa}, \mathrm{O}_{2}$ : arterial oxygen saturation; $\mathrm{V}^{\prime} \mathrm{O}_{2}$ : oxygen consumption; $\mathrm{V}^{\prime} \mathrm{CO}_{2}$ : carbon dioxide arterial tension; $V^{\prime} \mathrm{E}$ : minute ventilation; $V T$ : tidal volume; $f$ : breathing frequency; $t$ : inspiratory time; $t$ TOT: total breathing cycle. ${ }^{*}: p<0.05$ significant improvement from day 0 by paired $t$-test once a significant $f$ ratio was obtained by ANOVA for repeated measures across all visit days; ${ }^{\star *} p<0.01$.

presentation, with a mean CRQ-dyspnoea score of 2.4 in each group. In addition, there were no intergroup differences in lung volumes, expiratory flows (including FEV1), breathing patterns or metabolic variables at day 0 . The distribution of hospitalised versus outpatient presentations was similar in both subgroups i.e., four out of 12 recovered subjects and three out of eight nonrecovered subjects were hospitalised at day 0 .

Changes in dyspnoea, lung volumes and maximal flow rates during the study in the recovered group are presented in figure 2. In the 12 patients who recovered, there was a significant improvement in dyspnoea intensity between the first visit and the visit in which they reported that they had re-attained their baseline level of dyspnoea, with a recovery CRQ-dyspnoea score of $4.5 \pm 0.4 \quad(\mathrm{p}<0.01)$. These patients demonstrated a significant increase in FEV1 from $0.98 \pm 0.08 \mathrm{~L}$ at day 0 to $1.20 \pm 0.08 \mathrm{~L}$ at the recovery visit $(\mathrm{p}<0.05)$, with no change in FEV1/FVC. Consistent with an overall decrease in lung hyperinflation to the point of symptom recovery, the IC and SVC had increased significantly (both $p<0.01)$ in association with reductions in FRC $(p<0.05)$ and RV ( $p<0.01)$, respectively. There was no interval change in TLC. Aside from a significant reduction in breathing frequency $\left(-2.4 \pm 1.0\right.$ breaths $\left.\cdot \mathrm{min}^{-1} ; \mathrm{p}<0.05\right)$, there were no changes in steady-state breathing pattern from day 0 to symptom recovery. $\mathrm{Sa}, \mathrm{O}_{2}$ improved by $2.8 \pm 1.2 \% \quad(\mathrm{p}<0.05)$ during recovery in this subgroup.

In the eight patients who did not fully recover, there was a smaller $(\mathrm{p}<0.05)$ overall change in the CRQ dyspnoea domain score $(0.6 \pm 0.4)$ as compared with the recovered group $(2.1 \pm 0.5)$. In this subgroup, small increases in FEV1 and FVC between day 0 and the final visit did not reach statistical significance, although a significant reduction in lung hyperinflation was observed. IC increased by $0.31 \pm 0.08 \mathrm{~L}(\mathrm{p}<0.01)$, while FRC and RV fell by $0.28 \pm 0.09(\mathrm{p}<0.05)$ and $0.29 \pm 0.12 \mathrm{~L}$ $(p<0.05)$, respectively. It is important to note, however, that three patients within this subgroup subsequently experienced 

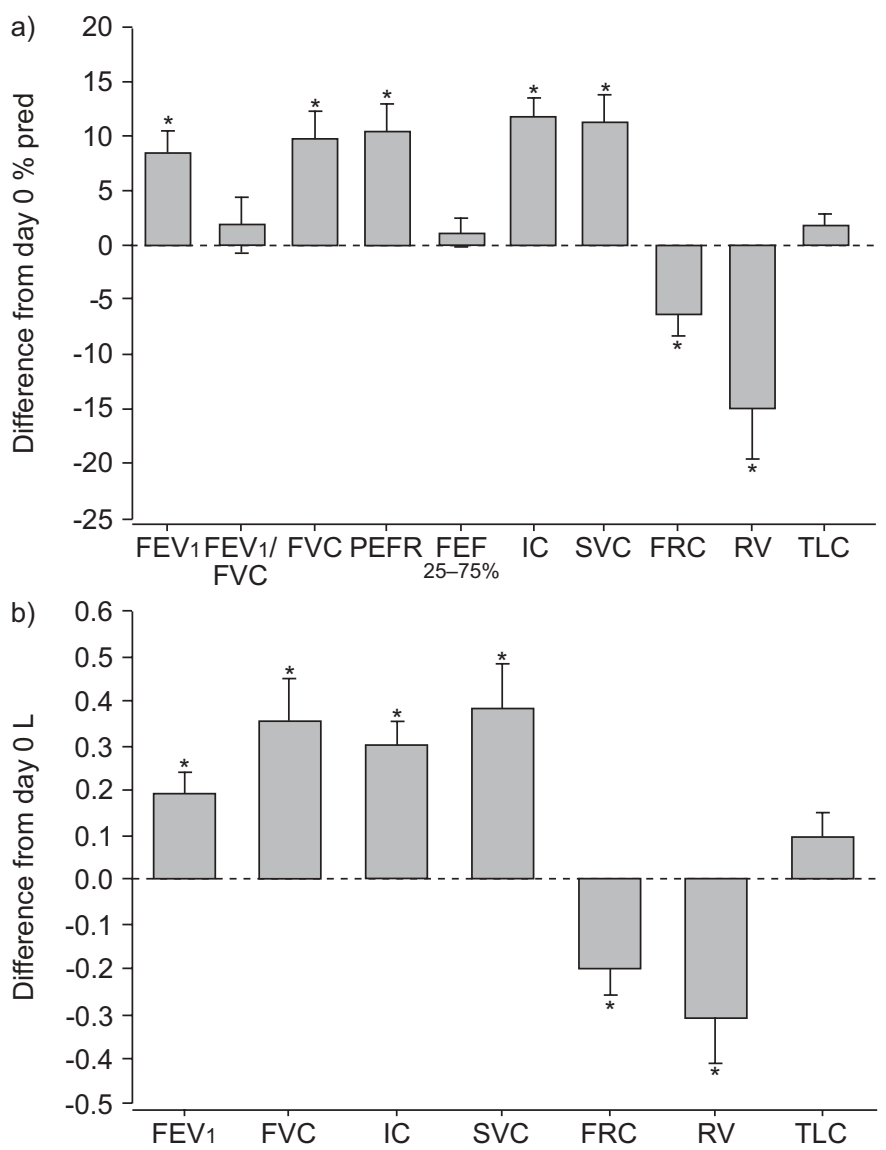

FIGURE 1. Changes in spirometric and lung volume measurements from day 0 to the final visit in all completed patients $(n=20)$. $F E V_{1}$ : forced expiratory volume in one second; FVC: forced vital capacity; PEFR: peak expiratory flow rate; FEF25-75\%: forced mid-expiratory flow; IC: inspiratory capacity; SVC: slow vital capacity; FRC: functional residual capacity; RV: residual volume; TLC: total lung capacity. * $\mathrm{p}<0.05$ difference from day 0 .

a worsening of their symptoms and withdrew from the study. Follow-up data obtained after the point of this symptomatic deterioration is, therefore, not available. Therefore, given the incomplete data set in this subgroup, no conclusion could be made about the direction of physiological change with time.

\section{DISCUSSION}

The present study has the following novel findings: 1) AECOPD, not associated with respiratory failure, is characterised by worsening airflow obstruction and lung hyperinflation with little change in resting ventilation, breathing pattern and metabolic parameters; 2) dyspnoea intensity at presentation, as measured by the $C R Q$, correlates well with spirometric flow and volume measurements; 3 ) improvement of dyspnoea following AECOPD is associated with reduction in lung hyperinflation (increase in VC and IC) and consequent increase in expiratory flow rates; and 4) change in IC reliably reflects change in EELV, as TLC remained unaltered during recovery from AECOPD.

Although there is no universally accepted definition of AECOPD, most current definitions allude to worsening symptoms as diagnostic criteria in patients with established
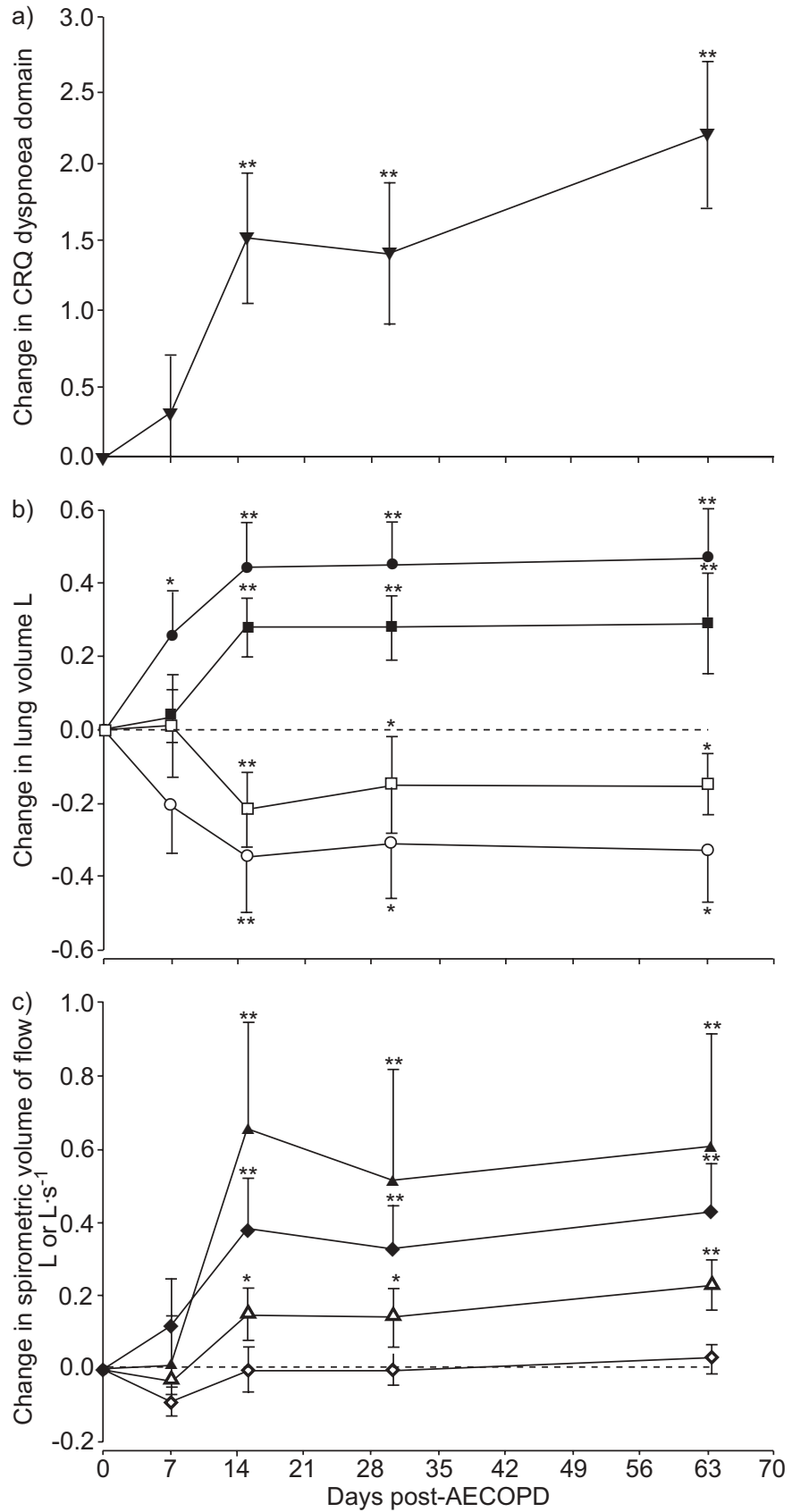

FIGURE 2. Changes in a) Chronic Respiratory Disease Questionnaire (CRQ) dyspnoea, b) lung volumes and c) spirometric measurements are shown during recovery from acute exacerbations of chronic obstructive pulmonary disease (AECOPD) in the subgroup that reached symptom-recovery during the study period ( $n=12$, except day 7 data only available in $n=7$ ). $\bullet$ : slow vital capacity; $\mathbf{\square}$ : inspiratory capacity; $\square$ : functional residual capacity; $\bigcirc$ : residual volume; $\mathbf{\Lambda}$ : peak expiratory flow rate; : forced vital capacity; $\triangle$ : forced expiratory volume in one second; $\diamond:$ forced mid-expiratory flow. ${ }^{*}: \mathrm{p}<0.05$ significant difference from day $0 ;{ }^{*}$ : $p<0.01$.

COPD [16]. In practice, physiological impairment is rarely quantified during AECOPD and the diagnosis is generally made on history alone. In keeping with previous studies [3-5], dyspnoea was the dominant presenting symptom and was present in all patients. Cough and increased sputum production or sputum purulence were also commonly reported. 
This study differs from most previous physiological studies in AECOPD in that patients were studied with less severe exacerbations who did not have acute respiratory failure at presentation. The study patients are, therefore, more representative of the majority of patients presenting to healthcare professionals for treatment of AECOPD. Of the study population, $65 \%$ were treated by family physicians in their offices and referred to the laboratory for physiological testing as soon as possible after diagnosis. The remaining seven patients were briefly admitted to hospital, but did not require any type of MV. An additional nine patients referred with the suspected diagnosis of AECOPD were excluded because they did not meet the spirometric criteria for COPD and their acute symptomatic deterioration could be explained by alternative diagnoses such as pneumonia.

The dyspnoea component of the CRQ was used to measure dyspnoea and its recovery as it complies with the principles of psychometrics and allows a comparison of dyspnoea at a standardised stimulus, i.e. during common activities of daily living that are important to the individual. The CRQ is also easily administered over long time spans, which is desirable because dyspnoea as a result of AECOPD can persist for weeks $[4,5]$. This instrument has previously been validated for use during AECOPD [28]. An average CRQ score of 2.4 at presentation indicated that patients were "very" short of breath during their common activities of daily living. The perception of severe dyspnoea in these patients was corroborated by a self-rated magnitude of task questionnaire (MRC), as well as a second multidimensional questionnaire (BDI). Finally, a few patients were so dyspnoeic that they were not able to complete various physiological tests on their first visit.

Surprisingly little information is available on the pulmonary function abnormalities associated with AECOPD, modest but inconsistent reductions in PEFR, FEV1 and FVC have previously been reported $[4,28,29]$. Tests at study entry indicated that the COPD patients had moderate-to-severe airway obstruction (average FEV1; 41\% pred) and lung hyperinflation (an elevated TLC, FRC and RV) during their exacerbation. Mild hypoxaemia, an increased ventilatory equivalent for $\mathrm{CO}_{2}$, as well as an increased estimated physiological dead space suggest the presence of associated gas exchange abnormalities. However, detailed analyses of arterial blood gases were not performed to confirm this possibility, since the majority of patients had an adequate resting $\mathrm{Sa}_{2} \mathrm{O}_{2}$ while breathing room air. Nevertheless, on average, resting ventilation, breathing pattern, $V^{\prime} \mathrm{O}_{2}$ and $V^{\prime} \mathrm{CO}_{2}$ were all within the normal range.

To further characterise the physiological abnormalities during AECOPD, pulmonary function, metabolic and breathing pattern parameters at study entry were compared with that of the final visit, an average of 60 days later (fig. 1). At presentation FEV1 and FVC were both reduced by 18 and $16 \%$ of the value at the final day; IC and SVC were significantly lower by 18 and 17\%, respectively; and FRC and RV were 5 and $11 \%$ higher, respectively. It is noteworthy that the FEV1/ FVC ratio did not change from day 0 to 60 , suggesting that the improvement in FEV1 mainly reflects the increasing VC. In other words, volume recruitment as a result of reduced airtrapping contributed to the increase in expiratory flow rates. Since TLC was unchanged during exacerbation and recovery, it follows that the change in IC can be used to reliably track the change in EELV. Differences in $V^{\prime} \mathrm{O}_{2}, V^{\prime} \mathrm{CO}_{2}$, ventilation and breathing pattern (including timing components) between first and final visits were small and inconsistent. Therefore, increased ventilatory demand and decreased expiratory time cannot easily be implicated as contributing to worsening lung hyperinflation during AECOPD in these flow-limited patients. By exclusion, the main cause of this acute-on-chronic hyperinflation is probably worsening of expiratory flow limitation. The large reduction in specific airway conductance, despite the higher absolute EELV at presentation, suggests the presence of significant dynamic airway dysfunction with compromised lung emptying for an unchanged expiratory time.

The exact time course of recovery of the various physiological parameters was not determined in the present study but, based on previous studies, is likely to be quite variable. SEEMUNGAL et al. [4] found that the median time to recovery of PEFR after an AECOPD was 6 days, but $25 \%$ of patients experiencing an exacerbation had not fully recovered to baseline PEFR by 35 days, and $14 \%$ of patients had not reached symptomatic baseline by 35 days. In the present study, improvements in dyspnoea and air trapping/hyperinflation were most marked by day 14 after exacerbation. Following day 14, further improvements in these parameters were much more modest. This suggests that, for the group as a whole, the bulk of recovery in symptoms and pulmonary hyperinflation was made within 14 days after the acute exacerbation. However, it should be stressed that improvements were not uniform in this cohort and, despite optimal management according to current published guidelines [2], eight out of 20 patients did not reach full symptom recovery after 60 days. Of these, three patients experienced a worsening of their symptoms consistent with a re-exacerbation, while five participants persevered in the study, but did not recover symptomatically by the end of the study period. Twelve of the study patients reported that they had fully recovered from their acute illness and that their perceived dyspnoea level had returned to its usual baseline by day 60 (fig. 2). The average CRQ rating of 4.5 at this subgroup's final visit represents a large clinically important improvement $[30,31]$, but indicates that they still experienced moderate activity-related dyspnoea. This CRQ rating is similar to that which has previously been reported in other studies in clinically stable COPD populations with similar FEV1 [28, 31].

As noted, treatment of exacerbations during this study was not standardised, but rather was prescribed in accordance with recently published clinical practice guidelines. As such, all patients in the study received either a new or an increased dose of inhaled bronchodilator, $90 \%$ received antibiotics and $60 \%$ received a new or increased dose of systemic corticosteroids. However, the specific drugs, dosages and durations of therapy were variable. The time interval between bronchodilator dosing and subsequent testing for each patient was standardised, as determined on day 0 . For the purposes of the current study, however, the current authors were interested in the physiological changes that accompanied recovery from an exacerbation of COPD, rather than the specific treatment modality used per se, but cannot exclude the possibility that some of the changes observed over time may have been influenced by the underlying treatments being utilised. 
The results support the contention that mechanical factors importantly shape the expression of dyspnoea during moderate AECOPD where abnormalities in gas exchange and ventilation (reflecting central respiratory drive) were small and less likely to contribute. A possible causal relationship between acute lung hyperinflation and dyspnoea intensity in COPD has been bolstered by a number of recent studies. Acute reductions in IC in asthmatics during bronchoconstriction [32, 33 ] and in COPD patients during exercise [34, 35] have been shown to correlate well with dyspnoea intensity ratings. During AECOPD, patients experienced similar levels of dynamic hyperinflation as during the increased ventilation of exercise, except that in the former situation such volume increases are sustained for days rather than minutes. A decrease in EELV (by $\sim 0.3 \mathrm{~L}$ or $18 \%$ ) during recovery from AECOPD in these mechanically compromised patients means reduced elastic loading and increased force generating capacity of the inspiratory muscles. Such improvements, in addition to reduced resistive loading, would be expected to reduce dyspnoea. An interesting observation to emerge from the current study is that improvement in indices of hyperinflation (such as increased IC) occur in conjunction with symptomatic improvement during recovery from AECOPD, and that improvements in expiratory flows (such as FEV1) appear to be secondary to the volume recruitment that accompanies this reduction in lung hyperinflation. Although the small sample size limits any definitive conclusions, these results support previous suggestions that reduction in lung hyperinflation may be a useful marker of symptomatic improvement following AECOPD [12, 36, 37]. From previous studies on the acute effects of bronchodilators the current authors have learned that small improvements in resting IC of the magnitude observed in this study (i.e. $0.2-0.4 \mathrm{~L}$ ) positively impact activity-related dyspnoea in COPD [38-40]. The present authors postulate that a similar rationale could be used to explain, at least in part, the improvements in the CRQ dyspnoea score that were observed over time in the present study.

\section{Summary}

This study extends previous studies of AECOPD by additionally measuring indices of lung hyperinflation. Moderate AECOPDs, characterised by severe dyspnoea (that was refractory to bronchodilator therapy) were associated with worsening acute-on-chronic lung hyperinflation, primarily as a result of increased expiratory flow limitation. Although dyspnoea in this setting is multifactorial, the current finding of a consistent association between recovery of dyspnoea and reduced lung hyperinflation (reflecting improved airway function) suggests that this was an important contributing factor. Other dyspnoea-provoking factors, such as worsening gas exchange abnormalities with attendant increases in ventilatory demand, appear to be less important, at least during these less severe exacerbations.

In conclusion, the study showed that simple spirometric inspiratory capacity measurements can be used to reliably evaluate the extent of lung hyperinflation during acute exacerbations of chronic obstructive pulmonary disease and its recovery with time. Finally, inspiratory capacity measurements provide clinically relevant information concerning the nature of pathophysiological impairment during acute exacerbations of chronic obstructive pulmonary disease and, thus, potentially complement traditional expiratory flow measurements in the assessment of severity.

\section{ACKNOWLEDGEMENTS}

The authors would like to thank L. Verton for technical assistance.

\section{REFERENCES}

1 Rodriguez-Roisin R. Towards a consensus definition for COPD exacerbations. Chest 2000; 117: Suppl. 2, 398S-401S.

2 O'Donnell DE, Aaron S, Bourbeau J, et al. Canadian Thoracic Society recommendations for management of chronic obstructive pulmonary disease -2003 . Can Respir J 2003; 10: 11A-65A.

3 Anthonisen NR, Manfreda J, Warren CP, Hershfield ES, Harding GK, Nelson NA. Antibiotic therapy in exacerbations of chronic obstructive pulmonary disease. Ann Intern Med 1987; 106: 196-204.

4 Seemungal TAR, Donaldson GC, Bhowmik A, Jeffries DJ, Wedzicha JA. Time course and recovery of exacerbations in patients with chronic obstructive pulmonary disease. Am J Respir Crit Care Med 2000; 161: 1608-1613.

5 Seemungal TAR, Donaldson GC, Paul EA, Bestall JC, Jeffries DJ, Wedzicha JA. Effect of exacerbation on quality of life in patients with chronic obstructive pulmonary disease. Am J Respir Crit Care Med 1998; 157: 1418-1422.

6 Barbera JA, Roca J, Ferrer A, et al. Mechanisms of worsening gas exchange during acute exacerbations of chronic obstructive pulmonary disease. Eur Respir J 1997; 10: 1285-1291.

7 Diaz O, Iglesia R, Ferrer M, et al. Effects of non-invasive ventilation on pulmonary gas exchange and hemodynamics during acute hypercapnic exacerbations of chronic obstructive pulmonary disease. Am J Respir Crit Care Med 1997; 156: 1840-1945.

8 Elliott MW, Aquilina R, Green M, Moxham J, Simonds AK. A comparison of different modes of noninvasive ventilatory support: effects on ventilation and inspiratory muscle effort. Anaesthesia 1994; 49: 279-283.

9 Girault C, Richard J-C, Chevron V, et al. Comparative physiological effects of noninvasive assist-control and pressure support ventilation in acute hypercapnic respiratory failure. Chest 1997; 111: 1639-1648.

10 Cinnella G, Conti G, Lofaso F, et al. Effects of assisted ventilation on the work of breathing: volume-controlled versus pressure-controlled ventilation. Am J Respir Crit Care Med 1996; 153: 1025-1033.

11 O'Donnell DE. Exertional breathlessness in chronic respiratory disease. In: Mahler DA, ed. Dyspnea. Lung Biology in Healthy and Disease. Vol 11. New York, Marcel Dekker, 1998; pp. 97-147.

12 O'Donnell DE, Webb KA. Exertional breathlessness in patients with chronic airflow limitation: the role of dynamic hyperinflation. Am Rev Respir Dis 1993; 148: 1351-1357.

13 O'Donnell DE, Bertley JC, Chau LKL, Webb KA. Qualitative aspects of exertional breathlessness in chronic 
airflow limitation: pathophysiologic mechanisms. Am J Respir Crit Care Med 1997; 155: 109-115.

14 Bhowmik A, Seemungal TAR, Sapsford RJ, Devalia JL, Wedzicha JA. Comparison of spontaneous and induced sputum for investigation of airway inflammation in chronic obstructive pulmonary disease. Thorax 1998; 53: 953-956.

15 Keatings VM, Collins PD, Scott DM, Barnes PJ. Differences in interleukin-8 and tumor necrosis factor in induced sputum from patients with chronic obstructive pulmonary disease and asthma. Am J Respir Crit Care Med 1996; 153: 530-534.

16 Pauwels RA, Buist AS, Calverley PMA, Jenkins CR, Hurd SS, on behalf of the GOLD Scientific Committee. Global strategy for the diagnosis, management, and prevention of chronic obstructive pulmonary disease. NHLBI/WHO Global Initiative for Chronic Obstructive Lung Disease (GOLD) Workshop Summary. Am J Respir Crit Care Med 2001; 163: 1256-1276.

17 American Thoracic Society. Standards for the diagnosis and care of patients with chronic obstructive pulmonary disease. Am J Respir Crit Care Med 1995; 152: S77-S120.

18 Guyatt GH, Berman LB, Townsend M, Pugsley SO, Chambers LW. A measure of quality of life for clinical trials in chronic lung disease. Thorax 1987; 42: 773-778.

19 Borg GAV. Psychophysical basis of perceived exertion. Med Sci Sports Exerc 1982; 14: 377-381.

20 Brooks SM. Task group on surveillance for respiratory hazards in the occupational setting. Surveillance for respiratory hazards. ATS News 1982; 8: 12-18.

21 Mahler DA, Weinberg DH, Wells CK, Feinstein AR. The measurement of dyspnea: contents, interobserver agreement, and physiologic correlates of two new clinical indexes. Chest 1984; 85: 751-758.

22 American Thoracic Society. Standardization of spirometry: 1994 update. Am J Respir Crit Care Med 1995; 152: 1107-1136.

23 Morris JF, Koski A, Temple WP, Claremont A, Thomas DR. Fifteen-year interval spirometric evaluation of the Oregon predictive equations. Chest 1988; 93: 123-127.

24 Knudson RJ, Lebowitz MD, Holberg CJ, Burrows B. Changes in the normal maximal expiratory flow-volume curve with growth and aging. Am Rev Respir Dis 1983; 127: 725-734.

25 Crapo RA, Morris AH, Clayton PD, Nixon CR. Lung volumes in healthy nonsmoking adults. Bull Europ Physiopath Respir 1982; 18: 419-425.

26 Briscoe WA, Dubois AG. The relationship between airway resistance, airway conductance, and lung volumes in subjects of different age and body size. J Clin Invest 1959; 37: 1279-1285.
27 Burrows B, Kasik JE, Niden AH, Barclay WR. Clinical usefulness of the single-breath pulmonary diffusing capacity test. Am Rev Respir Dis 1961; 84: 789-806.

28 Aaron SD, Vandemheen KL, Clinch JJ, et al. Measurement of short-term changes in dyspnea and disease-specific quality of life following an acute COPD exacerbation. Chest 2002; 121: 688-696.

29 Niewoehner DE, Collins D, Erbland ML, for the Department of Veterans Affairs Cooperative Study Group. Relation of FEV1 to clinical outcomes during exacerbations of chronic obstructive pulmonary disease. Am J Respir Crit Care Med 2000; 161: 1201-1205.

30 Juniper EF, Guyatt GH, Willan A, Griffith LE. Determining a minimal important change in a disease-specific quality of life questionnaire. J Clin Epidemiol 1994; 47: 81-87.

31 Redelmeier DA, Guyatt GH, Goldstein RS. Assessing the minimal important difference in symptoms: A comparison of two techniques. J Clin Epidemiol 1996; 49: 1215-1219.

32 Lougheed MD, Lam M, Forkert L, Webb KA, O'Donnell DE. Breathlessness during acute bronchoconstriction in asthma: pathophysiologic correlations. Am Rev Respir Dis 1993; 148: 1452-1459.

33 Tantucci C, Ellaffi M, Duguet A, et al. Dynamic hyperinflation and flow limitation during methacholine-induced bronchoconstriction in asthma. Eur Respir J 1999; 14: 295-301.

34 Marin JM, Carrizo SJ, Gascon M, Sanchez A, Gallego B, Celli BR. Inspiratory capacity, dynamic hyperinflation, breathlessness, and exercise performance during the 6minute-walk test in chronic obstructive pulmonary disease. Am J Respir Crit Care Med 2001; 163: 1395-1399.

35 O'Donnell DE, Revill SM, Webb KA. Dynamic hyperinflation and exercise intolerance in chronic obstructive pulmonary disease. Am J Respir Crit Care Med 2001; 164: 770-777.

36 O'Donnell DE, Forkert L, Webb KA. Evaluation of bronchodilator responses in patients with "irreversible" emphysema. Eur Respir J 2001; 18: 914-920.

37 Liesker JJW, Wijkstra PJ, Ten Hacken NHT, Koeter GH, Postma DS, Kerstjens HAM. A systematic review of the effects of bronchodilators on exercise capacity in patients with COPD. Chest 2002; 121: 597-608.

38 O'Donnell DE, Lam M, Webb KA. Measurement of symptoms, lung hyperinflation, and endurance during exercise in chronic obstructive pulmonary disease. Am J Respir Crit Care Med 1998; 158: 1557-1565.

39 O'Donnell DE, Fluge T, Gerken F, et al. Effects of tiotropium on lung hyperinflation, dyspnoea and exercise tolerance in COPD. Eur Respir J 2004; 23: 832-840.

40 O'Donnell DE, Voduc N, Fitzpatrick M, Webb KA. Effect of salmeterol on the ventilatory response to exercise in chronic obstructive pulmonary disease. Eur Respir J 2004; 24: 86-94. 